\title{
ABSTRACTS of
} Working Papers in ECONOMICS

The Official Journal of the AWPE Database

Field Key

$i$

Abstracts of Working Papers in Economics 501

Series Index 600

Keyword Index

$$
611
$$

Permuted Title Index

622

\section{CAMBRIDGE} UNIVERSITY PRESS 